\title{
Changes in Human Population Characteristics and Environmental Change in the West Matogoro Catchment Area of Songea, Tanzania
}

\author{
Michael J. Haule \\ The College of Business Education, Dar es Salaam, Tanzania \\ Email: $\underline{\text { m.haule@cbe.ac.tz }}$
}

Received 3 June 2014; revised 14 July 2014; accepted 2 August 2014

Copyright (C) 2014 by author and Scientific Research Publishing Inc. This work is licensed under the Creative Commons Attribution International License (CC BY). http://creativecommons.org/licenses/by/4.0/

(c) $\underset{\mathrm{EY}}{\mathrm{B}}$ Open Access

\section{Abstract}

The study was carried out in West Matogoro Catchment Area (WMCA) of Songea, Tanzania, to establish whether for the period between intercensal periods 1978-1988 and 1988-2002, and between 2002 and 2005 characteristics of human population of the area had changed in terms of size, age structure and sex composition. In case it did, then the study had to establish whether such changes may be used to explain the observed forest cover change that occurred in the area. Establishing whether the observed changes were proportionate was important in linking the relationship among factors at hand. The study partly tested the thesis by Liu and others which linked human population changes and their implications to the panda habitat [1]. The findings indicated existence of changes in human population characteristics for the period under review. Variations in terms of population size, age structure and sex composition were realized. While growth was measured by the total population and size of age group of the environmentally active population as identified by the study by Haule, sex composition was determined by sex ratios [2]. The environmentally active age group included males aged 20 to 44 and females aged 10 to 44, i.e. the key actors in felling trees for farm expansion and for firewood respectively. Geographic Information System (GIS) evidence indicated progressive forest cover deterioration. When compared, the changes in human population characteristics and those of the forest cover were noted to be unproportional. Variations were in terms of increase in human population size and expansion of age group of the "actors" thus attributed to the augmenting deforestation. A positive relationship was demonstrated between population growth, expansion of age segment of the key actors and expanded deforestation. We reiterate that any sustainable measures to address the environmental issues should take into account changes in demographic characteristics of the in Situ population which forms the locus of the interface between population and environment. These factors signify the intensity and duration of the involved forces that characterize forest cover quality. 


\section{Keywords}

\section{Population, Development, Environment}

\section{Introduction}

Deforestation is a phenomenon generally related to human population growth, however, it is not known as to whether changes in human population characteristics, in terms of age structure and sex composition are related to it and how. Age structure and sex composition are innate characteristics of any population. These characteristics harbour the specific points of interface between people and their surrounding environment. It implies that involvement of a human being in activities that affect forest cover occur at a particular point in the timeline of one's life. This point is denoted by one's age.

The mode of involvement, i.e. in which type of activities one has to engage and how one actually to engages in the same type of activity are aspects largely dictated, if not influenced, by one's sex composition. Hence age structure and sex composition are considered to be the characteristics that bear influence on the nature and character of natural resource use, misuse and abuse by the local population. In this way population characteristics carry the potential to shape forest cover status. In the needful times, they become the active contributors to forest cover change.

Since people of different sex categories and age groups tend to interact differently with forest cover, it is imperative underscoring their contribution to deforestation phenomenon in a location specific setting. Such knowledge is hereby considered crucial in the formulation of sustainable conservation initiatives.

The main thesis of this article is that population does not come into interface with the environment as a unit, but in its disaggregated manner [3]. It, therefore, is found important to establish the existing relationship between human population characteristics, development and environment in a location specific situation so as to draw inferences to other parts of the world with similar social, economic and environmental conditions.

The fact that population is not a static entity calls upon us to investigate the changes and their implications to environmental change. Understanding of the link between proportions of changes in population characteristics as compared to changes in forest cover that occur in the same period generates a body of knowledge critical for facilitating the planning of more targeted conservation packages as the two variables are basic for the understanding of both the drivers and trends in forest cover change [4]. The author draws the findings from a chapter of his Ph.D. thesis on "Population Dynamics and Sustainable Forest Conservation" awarded by the University of KwaZulu-Natal in South Africa which constitutes the basis of this article.

\section{Literature Review}

Several studies concede on the rapid population growth which is closely linked to the environmental change, deforestation in particular. However, some studies have indicated paucity of detailed research on the relationship between demographic dynamics and conservation; important elements for sustainable natural resources management [1] [3]. Such studies advocate the anticipatory, preventive and proactive direction of resource management, which addresses the key dynamic aspects of the new systems level approach. They actually urge for "local community participation approach" which promotes a "sense of ownership" and "responsibility" on environmental resources [1] [5]-[7].

A study by Madulu named "Demographic Dynamics and Environmental Change: Case of Swagaswaga Game Reserve (SGR)", was conducted in the Kondoa district of Tanzania to underscore the existing link between population and environment. The study analyzed the SGR population characteristics, i.e. size, growth rates, migration and household size, and linked them to the status of the environment [5]. The study found that household size differed with the mean household size which was 5 . About $45 \%$ of the population was under 15 years with few aged people. Dependence ratios were below 100. Low intra-district migrations were observed to dominate. Land was acquired through clearing, inheriting, hiring and purchasing. Population pressure increased land demand. Encroachment of the SGR was mainly for farmland, charcoal making, lumbering and beekeeping. However, it should be noted that "slash and burn practice" did not always justify encroachment. The study was quiet on who actually fell trees and how much land was encroached, hence lacking the quantitative impact of population dynamics. Moreover, the study did not investigate the changes in population structure and its impact, nei- 
ther did it give the comparative analysis of the situation in respect of household size, sex composition and age structure.

A study by Liu and others named "Changes in Human Population Structure and Implications for Biodiversity Conservation" was conducted in Wolong area of China, where both panda and tree species were threatened [1]. The area had increased firewood consumption, i.e. from 4000 to $10,000 \mathrm{~m}^{3}$. In two decades panda habitat was destroyed by 20,000 ha. Although human population size rose by $15 \%$ in 15 years, it was not clear as to whether human population structure had changed. The implications of the population and environmental changes for the panda habitat were to be established. Being part of the World International Man and Biosphere Reserve Network, Wolong was characterized by existence of the Han people, who in 1996, accounted for $70 \%$ of the population. Majority of villagers were farmers who used firewood as the main source of domestic energy. Between 1982 and 1996, the number of people of age group 20 - 59, which constituted the main labour force, increased by $59.67 \%$; while that of very old people, i.e. $60+$ years increased by $24.47 \%$. On sex ratio, two notable changes were made. The sex ratio of children aged 0 - 4 changed from 0.98:1 to 1.2:1 in 1996. Sex ratio of the old age, i.e. $70+$ was $0.57: 1$ in 1982, but increased to 0.98:1 in 1996. Between 1982 and 1996, illiteracy dropped from $30.85 \%$ to $24.60 \%$. The percentage those with elementary school level was reduced from $55.10 \%$ to $47.94 \%$. Overall, the percentage of those beyond secondary education doubled from $14.04 \%$ in 1982 to $27.47 \%$ in 1996 .

Generally it was found that although the total population increased only by $14.65 \%$ from 1982 to 1996 , the labour force aged 20 - 59 jumped by $59.76 \%$. It implies that the rate of change in the labour force was three times higher than the rate of change in the total population. This sharp increase in the labour force was significant on human impacts on the panda habitat through harvesting timber trees, fuel-wood, and road constructions. The male-based youngest age groups had two implications for both future population dynamics and panda habitat. A survey on residents' opinions and attitudes towards relocation observed that most young people were willing to settle outside the reserve even before they got married, especially if they could receive a higher education or more job opportunities in the cities. Old age people supported and encouraged their children and grandchildren to obtain college education and then work outside the reserve. Thus higher levels of education moved young people out of the reserve hence reduce impacts on the panda habitat. Moving one young person out of the reserve is equivalent to relocating a number of people overtime, as they consist of the sexually active subgroup. The study concluded that while population structure changes are a common phenomenon and biodiversity loss is becoming increasingly severe, research on the linkages between population structural changes and biodiversity conservation is lacking. This is the basis of this study conducted in WMCA of Songea, Tanzania.

Studies by Holden and Ehrlich [8] and Liu and others [1] found no demographic studies that sufficiently linked changes in population structure and their possible impacts in biodiversity therefore demonstrating paucity of knowledge in the area. However a study by Liu and others limited itself to identifying the impact of changes in population structure without considering the key actors. Lack of such information confirms the gap of knowledge, deemed important to be filled for sustainable conservation planning; or else, like its predecessors, it still generalizes the population-resources interface. Small scale studies are perceived significant in providing data and information on those who are part and parcel of the observed deforestation to ascertain the causative factors and effects within the respective setting [1].

Harrison argues that it is easy to ascribe blames in complex situations like considering "slash and burn" agriculture system with rapid population growth. It is easy to attribute population growth was a sole cause of deforestation. But this is an oversimplification [9]. Improvement of technology, in line with population growth might not need for more forest destruction to feed more people. Other factors could be declined in commodity prices, misguided government policy, which control prices and markets. But these were as well oversimplifications, since in case population was not growing there would be no need to clear new land even if fertilizers and high yield varieties were not used!

A study by Tiffen and others emphasized the same when it concluded that "more people" caused "less erosion". The study found that with population increase, people adopt were intensive cultivation practices, therefore reducing land degradation [10]. However, case studies conducted in six countries of Africa, including Tanzania, showed that Tiffen's thesis was far from generalization as most cases proved it not applicable. The Tiffen's "More People Less Erosion" hypothesis was proven applicable in some specific locations, especially with highly intensive farming practices that are related to water resource management [11]. Boserup's Model, as well, postulated an increase in land use intensification in line with population increase, which goes with more farm inputs 
and reduced fallow periods [12]. Despite lack of possibility for generalization of results, location-specific studies have proved to be more practical for problem solving other than general theories that cannot be easily applicable [9]. Whether the Tiffen's hypothesis holds in the context of Songea was an aspect to be established.

The study conducted in USA by Orians and Skumanich named "The Population-Environment Connection" [3] analyzed the disaggregated population component parts and drew the linkages among them and the environment. The population components dealt with were size, distribution, age structure, racial ethnic identity, socio-economic status, migration and household composition. The study noted that by responding to changing demographic structure of the population, i.e. its size, distribution, and composition, a more improved understanding of the way population shapes today's environmental problems; and those likely to be faced tomorrow may be unveiled. The location, timing and magnitude of environmental problems and issues, and the resultant types of problems that emerge are affected by these population components. The consequences of population change need to be investigated by studying the detailed demographic aspects such as changes in the structure, and basing on how they are measured by population analysts; and link them to how they pose a type of change in the environment over time. Age structure, shaped by number of people born and dead each year in each age group, and the number of migrants entering and leaving each age and sex category, tend to implicate on the environment, for increased consumption patterns.

The findings indicated that in the USA, age composition changed as births, deaths and net immigration alter the numbers of people in each age group resulting into aging of the population. It was observed that both education and income affect both vital rates and migration patterns. Higher fertility discourages employment, and employment discourages fertility, with the result that women in the labour force have, and expect to have, fewer children than women who are not in the labour force [3]. Household composition and family size constitute a unit for market demand analysis since family is the primary unit for consumption of commodities. However, the study does not explain on the variation in family size, and its respective impact to the demand on energy and other products. It is thought that a great potential for expansion of settlements and consequent impacts on natural areas exists with increasing numbers of households, their size and composition; hence demonstrating links between population and resources. Studies that emphasize on population size and density do not unveil the innate population-resource relationship. This study therefore linked population structural changes and their possible impacts on biodiversity saw the urgent need to investigate on the "un-chartered field" critical for sustainable development planning. Being a national level study, the down-to-earth relationship between population and environment could not be established due to the inherent spatial variation of factors that characterize the generality of the findings [3].

Lori Hunter synthesizes the current knowledge on the influence of population dynamics to the environment when examining the relationship between demographic factors, i.e. population size, distribution and composition, and environmental change [13]. The study included the role of mediating factors that influence this relationship, i.e. technological, institutional, policy and cultural forces. The study focused on two specific aspects of the environment i.e. climatic change and land-use change, and their implications for policy and further research. It concluded that population dynamics have important environmental implications, and that sheer size of the population represents only one important variable of the complex relationship. Population distribution posed implications to the environment on the fact that less developed regions could not cope with the growing share of the population thus, increasing intensification on the already dwindling resources. Population composition is a factor for environmental change as different population subgroups behave differently. The study findings revealed that a population with a large number of a cohort of young people, aged up to 24, and a large proportion of elderly will constitute different behaviours leading into different environmental implications. Though the findings are not negated, generality of the study findings call for a more detailed analysis. Adoption of interdisciplinary approaches that apply GIS in a small locality would produce more scientific enquiry on the links between social and natural processes.

At this point, it is evident on need for further studies linking population dynamics and environmental change for critical addressing the paucity of knowledge on population-resource relationship. Examining the relationship between population, environment and development, within the framework of the ongoing economic globalization remain indispensable [14]. Relative aspects of environmental conservation and degradation need to be discussed for sustainability. In Africa, a continent in which population growth and environmental degradation are experienced at unprecedented rates, studies of this nature is a necessity. 


\section{Methodology}

\subsection{Study Design}

This study was both quantitative and qualitative. It made use of both primary and secondary data. Primary data used were both quantitative and qualitative. Quantitative data were collected through household survey conducted in 2005 covering eight out of eleven villages of the WMCA, i.e. Lihwena, Chemchem, Ndilima Litembo, Muungano, Lipaya, Mahilo and Kikunja, while qualitative data were collected through Participatory Rural Appraisal (PRA) and observation. It included $40 \%$ of the 699 households found in the area. The breakdown of the sample households is presented in Table 1. The household survey data formed the basis of the analysis. Information was collected on the participation of all household members in activities related to deforestation and tree planting. All the participant households had a total of 3371 members, whereby 1690 were males and 1681 females.

Participants of the PRAs were selected based on gender mix, age groups, sub-villages, and one's position in the village, nature of economic activity, social practice and culture. Purposeful sampling was used in participant selection as it guaranteed the maximum variation. Specific approaches and techniques used during PRAs included dialogue that utilized fill in blanks, pair-wise ranking, cause and effect diagrams and trend analysis. The number of participants is as presented in Table 2.

Observation method was used to collect general information on various issues on population distribution, set

Table 1. Population sample in the eight villages covered by the study.

\begin{tabular}{|c|c|c|c|}
\hline Villages & No. of Households & Sample Size & Percentage \\
\hline Chemchem & 282 & 95 & 13.6 \\
\hline Mahilo & 141 & 65 & 9.3 \\
\hline Mpingi & 262 & 103 & 14.7 \\
\hline Ndilima Litembo & 185 & 69 & 9.9 \\
\hline Kikunja & 245 & 85 & 12.2 \\
\hline Lihwena & 161 & 114 & 16.3 \\
\hline Muungano & 252 & 58 & 8.3 \\
\hline Lipaya & 200 & 110 & 15.7 \\
\hline Total & 1728 & 699 & 100 \\
\hline
\end{tabular}

Source: Field Survey, 2005.

Table 2. Participants of the participatory rural appraisal by villages.

\begin{tabular}{ccc}
\hline Villages & Expected & Actual \\
\hline Chemchem & 12 & 14 \\
Mahilo & 12 & 8 \\
Mpingi & 12 & 12 \\
Ndilima Litembo & 12 & 9 \\
Kikunja & 12 & 11 \\
Lihwena & 12 & 11 \\
Muungano & 12 & 23 \\
Lipaya & 12 & 12 \\
& 96 & 100 \\
\hline
\end{tabular}

Source: Field Survey, 2005. 
tlement patterns, village layouts, farming and forest practices and social systems. Spot observation was carried out at specific sites such closed woodland forest and the West Matogoro Forest Reserve (WMFR).

Secondary data used included population data extracted from national population censuses data for 1978, 1988 and 2002. The data were analyzed to establish changes in human population size, age structure and sex composition through time.Data on forest cover change were obtained through GIS for years 1978, 1988, 2002 and 2005 are as indicated in Table 3.

\subsection{Data Analysis}

Changes in the human population were analyzed based on the actors in deforestation-related activities as identified in the study by Haule [2], i.e. those males aged between 20 and 44, and females aged between 10 and 44 . Changes were tracked in terms of its size, age structure and sex composition for censuses data 1978, 1988, 2002; and survey data for 2005. The aim was to determine the trends and changes in population characteristics to establish the variations that were compared to changes in forest cover characteristics demonstrated by GIS data of the same period. Data from Household Field Survey and the Participatory Rural Appraisal (PRA) were analyzed at spot and trend levels.

Behaviours of household members that had an impact to the environment were recorded and analyzed by age groups and sex categories. Survey data were extrapolated for 1978, 1988 and 2002 censuses data to determine both changes in population characteristics and the environment. Since cultural values and customs take long time to change, division of labour, which was based on age and sex assumed continuity. It was envisaged that the kind of division of labour observed remained the same for the entire period under review.

The complexity regarding deviations in engaging in environmentally-related behaviors within specified age groups, between the age groups and sometimes even within a single age group with time, were issues taken into consideration in the analysis.

The method adopted in the analysis of people's engagement in deforestation related activities was actually based on the understanding of the modus operandi of the members of the population on the environment. It is assumed that household members, by age groups or sex categories classified as key actors, behaved in a similar way when they interacted with the environment in terms of both the intensity and the duration of such activities that shape location-specific the forest cover characteristics [2]. Analysis of the survey data, regarding the key actor groups in terms of age groups and sex categories were adopted for simultaneous comparison using the same data as the baseline. The key actors in specific activities, tailored with qualitative information, obtained from PRA results, enabled the identification and the sizing of the key actor groups that were adopted for the comparative analysis, i.e. in determining trends in changes in population characteristics and the status of forest cover over years. Understanding the quantitative variations in the population characteristics was considered of significance in comparing changes in both population and environmental phenomena. In this case, a focus was on forest cover change.

\section{Presentation and Discussion of Findings}

Survey data demonstrated changes in numbers of the key actors in specific deforestation-related activities. This was achieved by analyzing the proportionate changes in sizes of key actors' segments over time, based on data extracted from the Tanzania National Population Census of 1978, 1988 and 2002 [15]-[17]. The specific findings are as described hereunder:

Table 3. Population characteristics and involvement in farm expansion 1978-2005.

\begin{tabular}{ccccc}
\hline Years & Population & Key Actors & Sex Ratio & Same Sex Proportion \\
\hline 1978 & 11.947 & 2.227 & 98.6 & 37.5 \\
1988 & 12.979 & 2.480 & 96.4 & 38.9 \\
2002 & 19.446 & 5.805 & 95.6 & 43.6 \\
2005 & 3.371 & 706 & 100.5 & 41.8 \\
\hline
\end{tabular}

Source: Tanzania National Population Census Report, 2003; Field Survey, 2005. 


\subsection{Changes in Age Structure and Sex Composition of Key Actors in Deforestation-Related Activities}

The study found it important to establish changes in key actors' population characteristics, i.e. age structure and sex composition, as it is critical in calculating the magnitude of such changes and the associated impact on changes in the forest cover for the years under review, i.e. between 1978 and 2005.

\subsubsection{Changes in Age Structure of Key Actors in Deforestation by Specific Activities}

(a) Key Actors in Clearing the Forest for Farm Expansion

Survey data demonstrated an increase in the size of the population segment of the key actors in farm expansion which constituted males, aged between 20 and 44. In 1978 there were a total of 2227 household members in the key actors' category constituting 18.6\% of the total population. Between 1978 and 1988 a segment of the key actors grew slightly to constitute $19.1 \%$, marking an increment of $0.5 \%$. The proportion of the key actors rose by $2.2 \%$ in the period between 1988 and 2002, meaning from 2480 to 4150 people. Using survey data and village vital statistics, registers for 2005 , the proportion of the key actors was about $2.1 \%$ indicating a decrease of $0.3 \%$ from that of 2002 .

The general trend in numbers of key actors indicated an increase in the proportion of the key actors to the respective total population by 2.7 between 1978 and 2002. When the data for 2005 were included, where a decline of $0.3 \%$ was observed, thus the net effect was a total increase of $2.5 \%$ in the size of the key actors' group between 1978 and 2005. Since data on the total population for 2005 were obtained from the vital registration, which are subject to criticism due to unreliability caused by the possibility, there is a possibility for understatement [18].

It is the contention of this study to argue that the increase in the key actor population could largely be attributed to the proportionate increase in the population size. Figure 1 illustrates the same finding as there was correspondence between the changes in key actors segments and trends in total population changes for years under review.

(b) Key Actors in Clearing the Forest for Collecting Firewood

Survey data indicated changes in key actors in the activity of felling trees for chopping firewood. Changes were noted in terms of both the numbers and proportions of the respective total human populations. In 1978 the population of key actors in the activity, i.e. females aged between 10 and 39 , was 3125 , which constituted $26.1 \%$ of the total population. Their proportion grew by $0.9 \%$ between 1978 and 1988, i.e. from $26.5 \%$ to $27 \%$ respectively. Between 1988 and 2002 the key actors' population grew by $3.8 \%$, meaning from $27 \%$ to $29.8 \%$ respectively, implying a net increase of about $4.7 \%$ in the proportion of the key actors.

However, a drop in the proportion of key actors of $2.4 \%$ was noted between 2002 and 2005, i.e. from $29.8 \%$ to $27.4 \%$ respectively. The observed a drastic drop in the proportion of the key actors observed in 2005 was attributed to unreliability of vital registration data characterized by the possibility of understatement of vital events. The decline could, as well, result from rapid urbanization of Songea Municipality especially in peri-urban settlements such as Chemchem, Lihwena and Muungano all of which experienced acute firewood shortage. Such

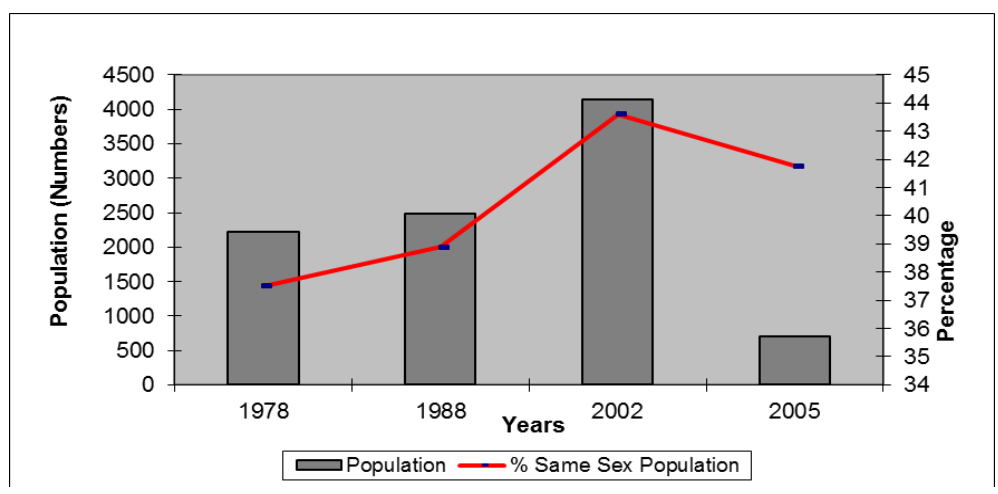

Figure 1. Total population of key actors in converting forests into farms by numbers and sex composition 1978-2005. Source: Tanzania National Population Censuses 1981, 1990 and 2003 and Field Survey, 2005. 
settlements increasingly depended on firewood bought by mobile firewood vendors. PRA results indicated that in the study area urbanization did not bring about a significant shift in terms of types of energy sources. It merely augmented firewood scarcity as the forest was extensively and intensively cleared to accommodate human settlements in areas previously covered by the forest. The tendency was towards commoditization of firewood. National statistics indicate that only $24 \%$ of households of Songea urban were connected to electricity [19]. Even those with the electricity connection, a significant proportion of them did not use it for cooking due to prohibitive electricity tariffs, thus perpetual dominance of fuel wood use.

The national rate of urbanization for Tanzania, between 1978 and 1988 was 53\%, making it among the fastest urbanized countries in SSA [20] [21]. By mid-2005, the town of Songea was granted municipality status, meaning that its boundaries expanded to occupy larger spatial areas formerly designated as 'rural' which included Muungano and Lipaya villages. With such changes in land use, i.e. from rural to urban, consumption of firewood remained high, despite the noted decline in numbers of the "collectors". In this case, it was imperative to mention that in WMCA urbanization did not reduce deforestation, though it could significantly reduce the numbers of key actors in the activity. In peri-urban areas, the number of key actors in felling trees for chopping and firewood collecting decreased, while at the same time, the process apparently intensified in suburbs as more farm and forest areas were converted into other uses mainly human settlements. The firewood collectors in the suburban areas had to 'produce firewood' at two levels, i.e. for their own households and for sale.

Survey data indicate that the net effect of changes in the human population structure of the key actors in felling trees for firewood marked an increase of $2 \%$ of the proportion. Figure 2 demonstrates the same. To establish whether the decline in the proportions of the key actors in the activity amounted to the decline in the volume of the activity is an important aspect this study would like to cover.

\subsubsection{Changes in Population Composition of the Key Actors in Deforestation-Related Activities}

\section{(a) Key Actors in Clearing the Forest for Farm Expansion}

The sex ratio of the key actors was an index used to determine sex composition of the key actors in the activity. The increase in sex ratio meant an increase in numbers of males compared to that of their female counterparts and vice versa.

Haule stipulates that the key actors in converting forests into farms, i.e. males aged between 20 and 44 [2]. The analysis of the human population data illustrated that the proportion of the key actors to the total number of people of the same sex category rose from $37.5 \%$ in 1978 to $38.9 \%$ in 1988, registering an increase of $1.4 \%$. It implies that within the period, the male actors in the same category (age groups and sex) had relatively increased in numbers.

Data in Table 3 indicates that between 1988 and 2002 there was an increase of $4.7 \%$ in the proportion of the key actors relative to the total number of males in the same group category. The proportion rose from $38.9 \%$ in 1988 to $43.6 \%$ in 2005. For the entire period under review, i.e. between 1978 and 2005, the number of key actors rose significantly by $6.1 \%$. The decline in the proportionate number of males engaged in felling trees for farm expansion of $1.8 \%$ was noted between 2002 and 2005, culminating into a relative decline in the numbers of males within the group of the key actors compared to the total number of males, hence showing existence of a

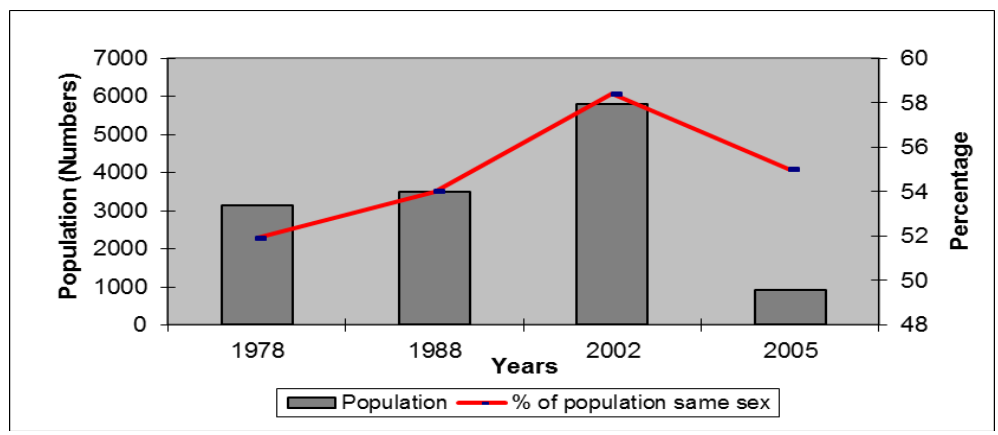

Figure 2. Total population of key actors in clearing the forests for collecting forest for collecting firewood by numbers and sex composition 1978-2005. Source: Tanzania National Population Censuses, 1981, 1990 and 2003 and Field Survey, 2005. 
positive relationship between the two variables. This may be attributed to urbanization and absence of vast open forest areas to be cleared.

When comparing the changes in the sex composition of the group of key actors and that of the total population, based on sex ratios, differences of significant levels were noted. Figure 3 demonstrates the comparison of the changes in proportionate numbers of key actors within the age group, while Figure 4 demonstrates the variations in sex composition within the key actors as related to the total population's sex ratio. Sex ratio that stood at $98.5 \%$ in 1978 declined to reach $96.4 \%$ in 1988 , i.e. a drop of $2.1 \%$, denoting a decline in proportion of males in the population.

The sex ratio declined again by $0.8 \%$ between 1988 and 2002, indicating further the decline in numbers of males relative to that of females, implying the decline in numbers of the key actors in farm expansion, therefore reducing chances for expansion of farms since the decrease of the numbers of such actors reduced the potential for the activity.

Figure 4 demonstrated a sharp increase in sex ratio by 4.9\%, which was observed between 2002 and 2005 implying a proportionate increase in numbers of males relative to that of their female counterparts. This portrays an increase in the possibility for fast rate of deforestation contributed by farm expansion whose key actors were noted to have been relatively increased in numbers. It also signaled a greater possibility for more deforestation. By this period there was less possibility for females to join the activity of expanding farms as their numbers tended to proportionately and steadily decline between 1978 and 2002. Females' involvement could have likely picked up in the period between 2002 and 2005, when numbers of males, i.e. actors dropped.

The above scenario indicates that while the number of the key actors, by their sex and age groups, had proportionately increased; the proportionate numbers of female counterparts had been consistently decreasing. The impact of the observed variations in population characteristics to forest cover changes, need to be established as it is critical for development of sustainable conservation packages.

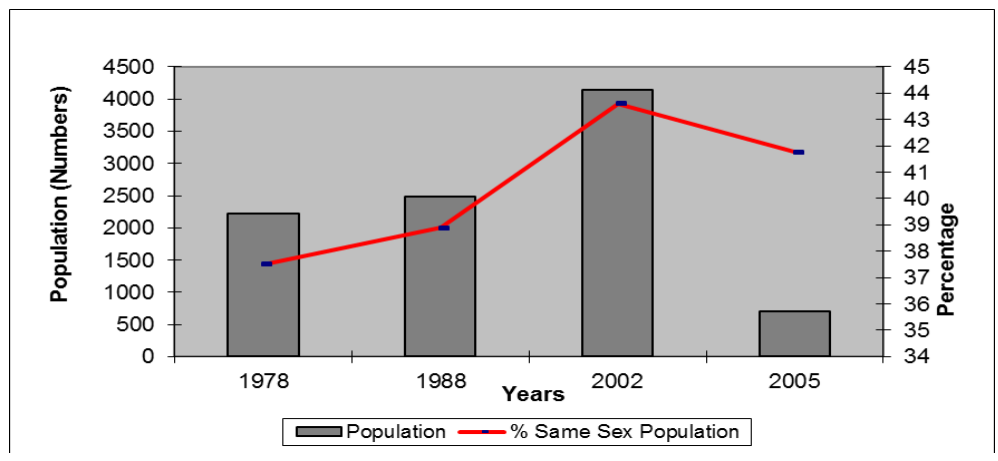

Figure 3. Total population of key actors in converting forests into farms by numbers and sex composition 1978-2005. Source: Tanzania National Population Census 1980, 1990 and 2003 and Field Survey, 2005.

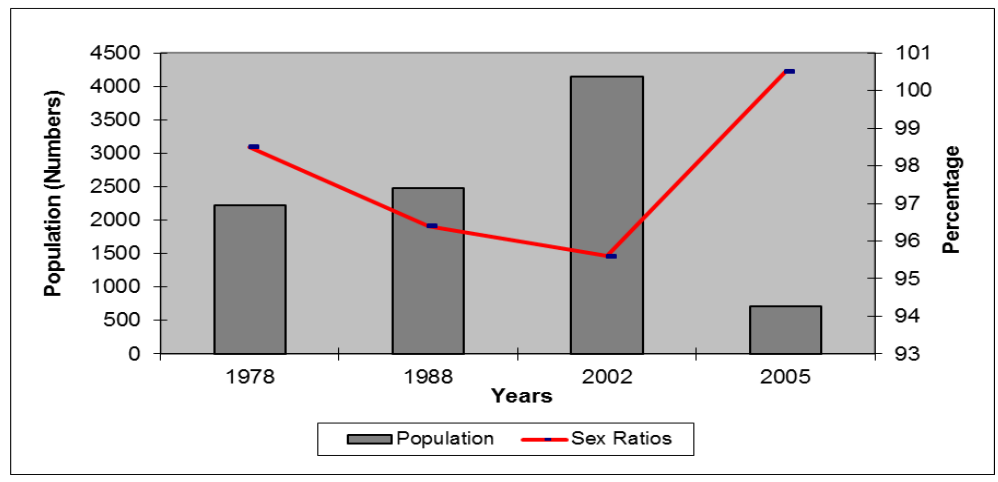

Figure 4. Variations in key actors in converting forests into farms by numbers and sex ratios 1978-2005. Source: Tanzania National Population Census, 1981, 1990 and 2003 and Field Survey, 2005. 
(b) Changes in the Population of Key Actors in Clearing the Forest by Collecting Firewood 1978-2005

The sex composition of the key actors in collecting firewood, i.e. females aged between 10 and 39, underwent significant changes between 1978 and 2002. In 1978 there were 3125 key actors who constituted 51.9\% of the total number of females in that year, implying that a larger proportion of females were actually engaged in the activity. The proportion rose to $54 \%$, i.e. an increase of $2.1 \%$ in 1988 . In 2002 the proportion of the key actors reached $58.4 \%$ recording an increase of $4.4 \%$. Figure 5 illustrates the changes in actors' population characteristics over time.

A fall of about $3.4 \%$ in the proportionate numbers of key actors was noted between 2002 and 2005. It means that within the period of three years, the numbers of females involved in firewood collection decreased despite the increase in number of women in the respective age group.

When linked with changes in sex composition of the total population, as demonstrated in Table 4, sex ratios declined from 98.5 in 1978 to $96.4 \%$ in 1988, showing that the numbers of males declined relative to that of females. Since females were the key actors in the activity of collecting firewood, basically from trees fallen by males, their proportionate increase does not necessarily imply presence of a greater potential for the activity to expand and aggravate deforestation through the activity. Data on changes in characteristics of the actors' population in collecting firewood relative to changes in sex ratios are illustrated in Figure 6.

The rise in the sex ratio between 2002 and 2005 portrays the presence of more males than females in the population. It implies that the proportion of females, the key actors in the activity of collecting firewood declined, hence less likelihood of reducing the pace of clearing of forest cover by firewood cutting, which is actually done by males. An account of impact of changes in population composition on forest cover change is another important aspect to be established by other studies.

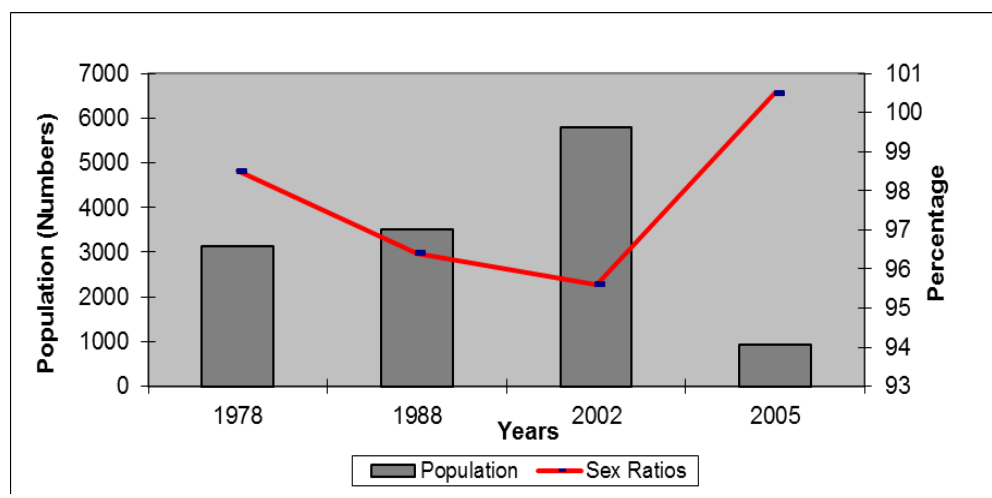

Figure 5. Variations in key actors in clearing the forest for collecting firewood by numbers and sex ratios 1978-2005. Source: Tanzania National Population Census, 1981, 1990 and 2003 and Field Survey, 2005.

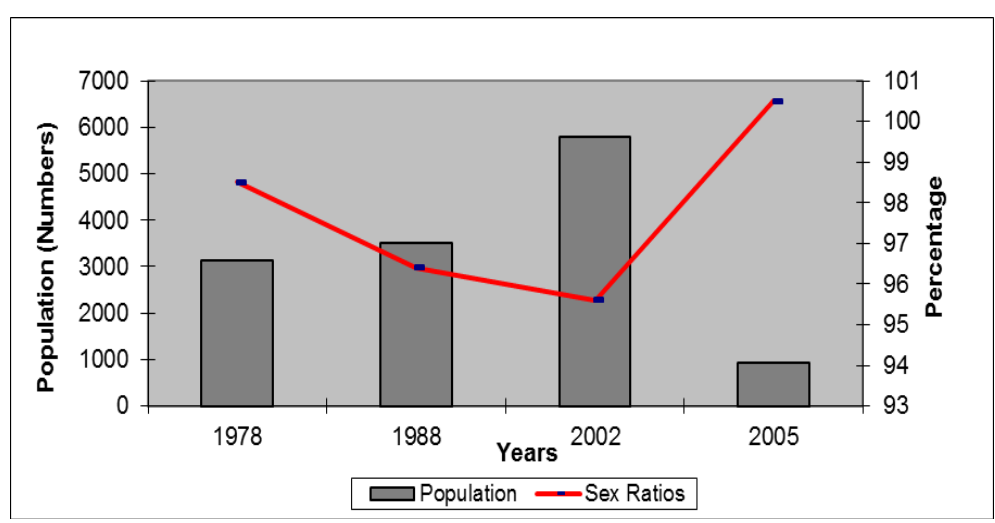

Figure 6. Variations in key actors in clearing the forest for collecting firewood by numbers and sex ratios 1978-2005. Source: Tanzania National Population Census, 1981, 1990 and 2003 and Field Survey, 2005. 
Table 4. Population characteristics and involvement in firewood collecting 1978-2005.

\begin{tabular}{ccccc}
\hline Years & Population & Key Actors & Sex Ratio & Same Sex Proportion \\
\hline 1978 & 11.947 & 2.227 & 98.6 & 37.5 \\
1988 & 12.979 & 2.480 & 96.4 & 38.9 \\
2002 & 19.446 & 5.805 & 95.6 & 43.6 \\
$2005^{* *}$ & 3.371 & 925 & 100.5 & 55.7 \\
\hline
\end{tabular}

Source: Field Survey, 2005. ${ }^{* *}$ Based on sample household's population.

\subsection{Changes in Population Characteristics of Key Actors and their Contribution to Forest Conservation Activities}

The main activity observed in forest conservation in the WMCA was tree planting. It is an effort to avail an alternative source of firewood and other forest-based resources to the population, thus conserving the already progressively dwindling natural forests. In such a way, planted trees reduced pressure on the natural forests, therefore implicitly contributing to conservation of natural forests.

Characteristics of trends in changes in the human population in terms of age structure and sex composition of the key actors based on size, relative to the members of the same age and sex segment, and the comparison of its variations relative to sex ratios of the entire population were established. A detailed analysis was performed to underscore the variability of the key actors' proportions by specific conservation activity for years 1978, 1988, 2002 and 2005. This information generated was considered critical in establishing the relationship between the changes in population characteristics and resulting changes in forest cover within particular space and time.

\subsubsection{Changes in Age Structure of the Key Actors in Tree Planting}

Data on numbers of individuals in specific age groups and sex categories, classified by Haule [2], i.e. males aged between 20 and 59, as the key actors in the activity of tree planting, varied with time between 1978 and 2005. In 1978 they were 2877 key actors who constituted $21.3 \%$ of the population of males in that age group and sex category. By 1988 the key actors' population rose by $0.9 \%$ while a relatively faster increase in the key actor segment of $1.9 \%$ was realized between 1988 and 2002 and a small rise of $0.3 \%$ was also recorded between 2002 and 2005.

General trends demonstrated in Figure 7 indicate a steady increase in numbers of males who entered the active age group in the activity between 1978 and 2002. However, the rate tended to decrease towards stabilization between 2002 and 2005. The trend portrayed the proportionate increase in male's involvement in tree planting between 1978 and 2002. Fewer people joined the activity by 2005.Trends in proportionate declines in numbers of key actors can be linked to the observed trends in numbers of planted trees, hence reducing replacement rate of natural forest cover, while at the same time adversely affecting the natural forest cover.

\subsubsection{Changes in Sex Composition of the Key Actors in Tree Planting}

Sex composition of population of the key actors, i.e. males aged 20 and 59; indicated changes. Data in Figure 8 demonstrates that in 1978 the proportion of the key actors to that of other males in the respective group was $42.9 \%$. Their proportion rose by $2.2 \%$ in 1988 indicating "entrance" of more people in that age segment, therefore raising the potential actors in tree planting. A faster rate of increase of $4.2 \%$, i.e. from $45.1 \%$ to $49.3 \%$ experienced between 1988 and 2002, implying further enhancement of the human potential in tree planting, hence likely to plant more trees. A slight decline in the proportion of key actors of $0.7 \%$ was noted between 2002 and 2005 indicating a slow decline in the proportion of those in the age and sex segment who dealt with tree planting, therefore likely to reduce the pace of involvement in the activity.

Figure 8 indicates further that in the period between 1978 and 1988 sex ratios declined by $2.1 \%$, i.e. from $98.5 \%$ to $96.4 \%$ respectively. Further decline of $0.8 \%$, i.e. from $96.4 \%$ to $95.6 \%$ was noted between 1988 and 2002. The observed decrease in sex ratio indicates a decline in the number of males relative to that of females who participated in the activity. Data in Table 5 indicates the population characteristics for the four years under review. 


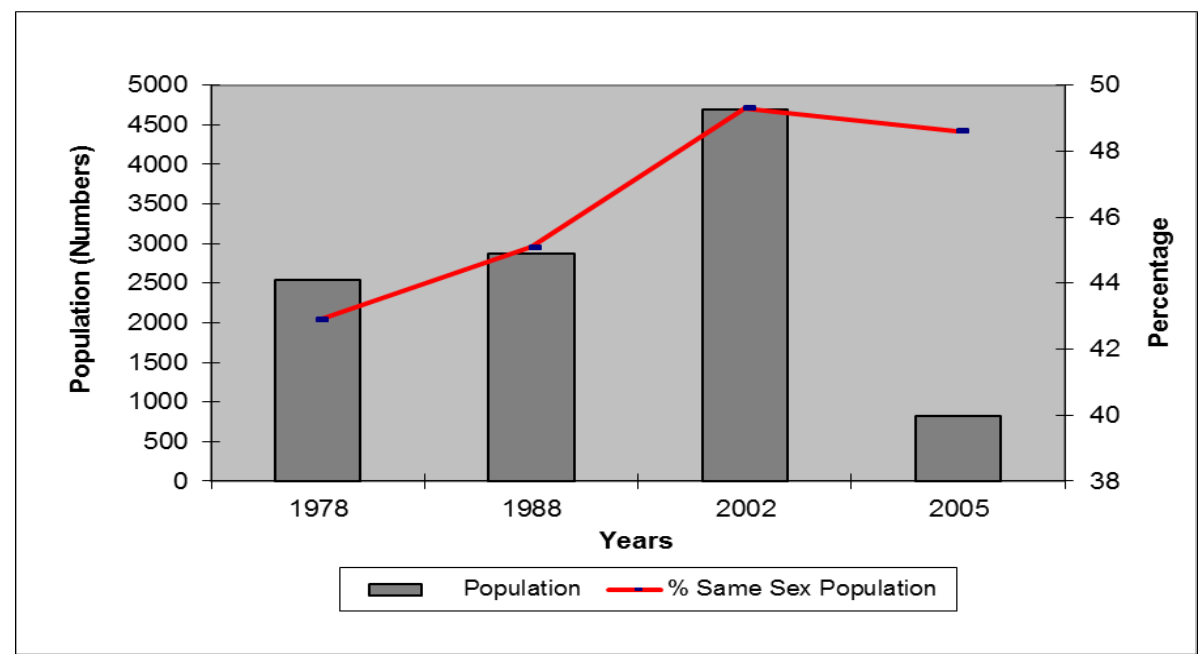

Figure 7. Total population of key actors in tree planting by numbers and sex composition 1978-2005. Source: Tanzania National Population Census, 1981, 1990 and 2003 and Field Survey, 2005.

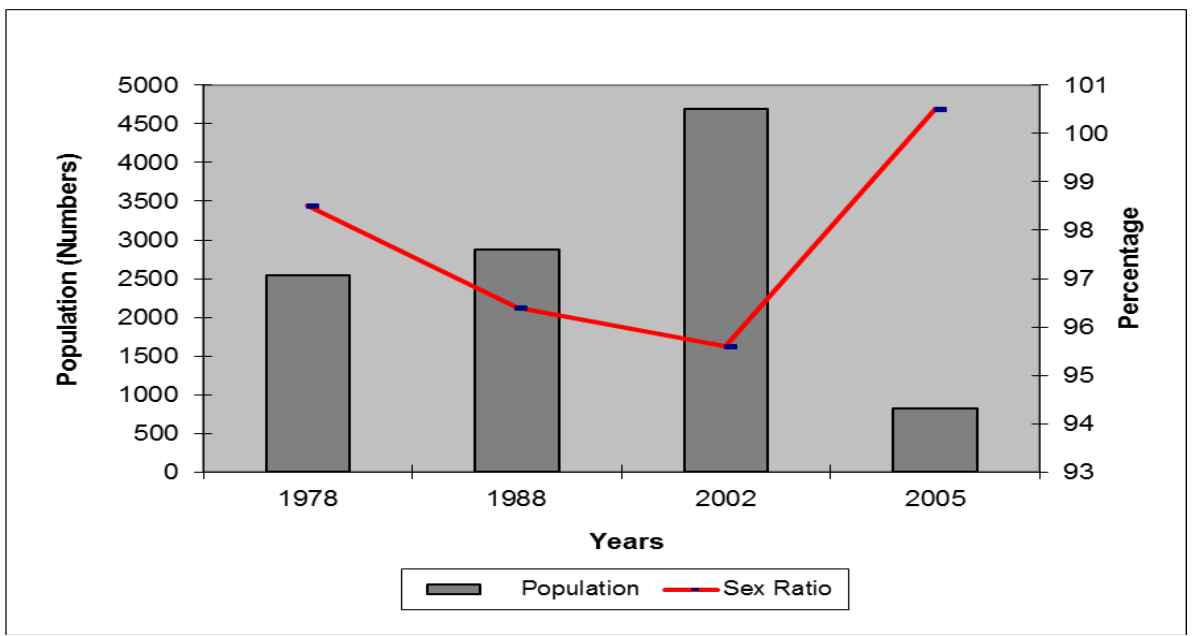

Figure 8. Variations in key actors in tree planting by numbers and sex composition 19782005. Source: Tanzania National Population Census, 1981, 1990 and 2003 and Field Survey, 2005.

Table 5. Population characteristics and involvement in tree planting 1978-2005.

\begin{tabular}{rrrrr}
\hline Years & Population & Key Actors & Sex Ratio & Same Sex Proportion \\
\hline 1978 & 11.947 & 2.227 & 98.6 & 37.5 \\
1988 & 12.979 & 2.480 & 96.4 & 38.9 \\
2002 & 19.446 & 5.805 & 95.6 & 43.6 \\
$2005^{* *}$ & 3.371 & 823 & 100.5 & 46 \\
\hline
\end{tabular}

Source: Field Survey, 2005. ${ }^{* *}$ Based on sample household's population.

A decline in the numbers of males, i.e. the key actors in tree planting meant, cateris peribus, reduced the possibility for the activity to expand. The decline in involvement in tree planting observed in WMCA could partly be attributed to the noted decline in the proportionate numbers of those involved and those in the active popula- 
tion segment but were actually not involved in the activity. Sex ratios demonstrated a rise of $4.9 \%$ from 2002 to 2005 , indicating a drastic rise in the number of males relative to that of their female counterparts. During the same period, the potential for tree planting had increased as the key actors representation had proportionately increased in numbers. The impact of changes in population characteristics of the key actors in activities that shape the forest cover constitutes an important aspect in trying to establish the existing relationship between population, development and environment in WMCA and possibly elsewhere.

\section{Conclusions}

From the above discussions, it was evident that there had been changes in the demographic characteristics particularly of those people involved in different development or livelihood activities which were observed in terms of their numbers and sex categories that lead to forest cover change. It implied that the interface of the population and forest cover differed by sex and age groups of the key actors. The demographic changes in the population subgroups can be directly associated with forest cover characteristics.

The observed changes were non-proportional for all the intercensal periods under review. While population size indicated mere variations or changes in the quantity of the actors in deforestation and conservation activities, sex ratios, i.e. the proportionate numbers of males to that of females, demonstrated the actual potential of the population to act on the environment, forest cover in particular.

It can be asserted that the increase in the population size alone cannot be a necessary and satisfactory factor to explain the status of quality of the forest cover. Variation in terms of sex composition of the key actors segments is considered an inert factor for the planning of sustainable conservation efforts and important stage towards achieving sustainable development.

The article underlines fact that the understanding of who actually cuts trees, and who actually plants the trees alone is not enough for the planning of sustainable conservation efforts, more important is tracking on how such age groups of such people change with time, hence being able to project the future environmental status. The tenet put forward at this point is that the ones who cut the trees do-se with reasons, so are those who plant trees, but more critical is being able to project the kind of environmental disaster they may cause, hence developing effective proactive conservation packages efforts to protect and prevent it from happening. To involve those who cut trees in tree planting is a challenge, but determining the factors and magnitude of the environmental problem, and exposing it to the right segment would make it practical and meaningful. In this way, they will be fully engaged in maintaining or improving the existing forest cover while conceptualizing the predicted future environmental status. The understanding of the reasons for cutting trees would be turned into an important extension message for the same actor to plant more trees to carter for the same known purpose. Understanding the demographic changes leads into better planning of environmental conservation programmes.

Information on the proportionate contribution of household members in deforestation, when linked to detailed information obtained through qualitative data analysis will provide better explanation on the existing relationship between population, development and environment. We emphasize that it is after the role of the key actors in deforestation process, which is estimated and made known that more light would be shed on to the analysis of the PDE relationship, hence making it more understandable for practical utility in sustainable forest conservation.

Changes in sex composition, demonstrated by sex ratios had an impact to both deforestation and/or conservation efforts. It may profoundly be argued that while changes in numbers of actors in forest cover change assures continuity of deforestation process, changes in sex ratios would tend to indicate intensity of the same process.

We reiterate that the understanding of variations and/or changes in population characteristics of the key actors in activities that lead to forest cover change is of pragmatic value in explaining the PDE linkages in WMCA and elsewhere. This will enable for the detailed understanding of mechanisms of deforestation process, hence considered to be of great utility in the formulation of more effective and sustainable conservation efforts. It, therefore, implies that by merely changing the population structure, through transfer of young men and girls to cities, accomplished through provision of higher education, as found by Liu and others [1], the forest cover of the WMCA and elsewhere may perpetually be maintained.

\section{Recommendations}

Basing on the above findings the study recommends that in the planning of sustainable environmental manage- 
ment should take into account changes in human population characteristics as they influence both the intensity and duration of the processes that culminate into environmental degradation, deforestation inclusive. Such knowledge is critical in projecting the future trends in environmental change.

Since changes in sex composition, measured in terms of sex ratio, and the changes in numbers of people in the active age segment engaged in deforestation-related activities have indicated some variations, we recommend that the actual implications to the forest cover change be investigated and documented for the better understanding of the existing relationship between population, development and environment. Such knowledge should be used in the planning of conservation activities.

More studies are recommended to be undertaken so as to such generate knowledge on the relationship between changes in human population characteristics and environmental change. Findings of such studies have to be used more precisely in addressing both the current and future adverse environmental phenomena.

As younger age population segment was observed harbouring the main actors in deforestation-related activities; targeting of conservation packages to people in the same age group sounds logical and effective. Younger age groups are to be effectively engaged the inclusion of environmental education in the educational system. Those who finish primary education have to obtain knowledge, skills and the rationale for forest conservation so as to build the basis for their positive attitudes and behaviours towards the environment. The knowledge should extend to cover the impact of population change on forest cover change; and other related consequent changes in terms of weather and on the river discharge.

\section{References}

[1] Liu, J., Ouyang, Z., Tan, Y., Yang, J. and Zhang, H. (2000) Changes in Human Population Structure and Implications for Biodiversity Conservation, Population and Sustainable Development. American Association for Advancement of Science (AAAS).

[2] Haule, M. (2013) Population, Development and deforestation in Songea District, Tanzania. Journal of Natural Resources, $\mathbf{5}, 15$.

[3] Orians, C. and Skumanich, M. (1997) Population-Environment Connection: What Does It Mean for Environmental Policy? USA Environmental Protection Agency.

[4] Haule, M. (2010) Population Dynamics and Sustainable Forest Conservation: A Case Study of the West Matogoro Catchment Area in Songea, Tanzania. Ph.D. Thesis, University of KwaZulu-Natal, South Africa.

[5] Madulu, N. (2001) Population Dynamics and sustainable Conservation of protected Areas in Tanzania: The Case of Swagaswaga Game Reserve in Kondoa District.

[6] URT (1997) Ruvuma Regional Socio-Economic Profile. Government Printers, Dar es Salaam.

[7] URT (1998) General Overview of Land Use in Tanzania: From a Forest Point of View. Ministry of Natural Resources and Tourism. Dar es Salaam.

[8] Ehrlich, P. and Holden, J. (1971) Impact of Population Growth. Science, 171, 1212-1217.

[9] Harrison, P. (1997) Is Sex and the Single Planet. In: Goldfarb, T., Ed., Taking Sides on Environmental Issues, 7th Edition, Dushkin/ McGraw Hill, New York, 86-92.

[10] Tiffen, M, Gichuki, F. and Willey, J. (1994) More people, Less Erosion: Environmental Recovery in Kenya. Wiley, Chichester.

[11] Boyd, C. and Slaymaker, T. (2000) Re-Examining the More People Less Erosion Hypothesis: Special Case or Wider Trend? Natural Resource Perspectives, No. 63, Overseas Development Institute. http://www.odi.org.uk/nrp

[12] Boserup, E. (1981) Population and Technology Change. Chicago University Press, Chicago.

[13] Hunter, L.M. (2001) The Environmental Implications of Population Dynamics. RAND Corporation, Santa Monica.

[14] Martine, G. (1996) Population and Environment in the Current Development Scenario. Working Paper Series, No. 96.

[15] United Republic of Tanzania (1981) The 1978 Population Census Report Vol. 2, Population by Age and Sex for Villages/Wards and Urban. Ministry of Planning and Economic Affairs, Dar es Salaam.

[16] URT (1990) The 1988 Population Census-Ruvuma Regional Profile. President's Office-Planning Commission, Dar es Salaam.

[17] URT (2005) 2002 Population and Housing Census: Village and Street Statistics, Age and Sex Distribution in Ruvuma Region. Vol. 7, President's Office Planning and Privatization, Dar es Salaam.

[18] United Nations (2010) Status of Civil and Vital Statistics in SADC Region. A Technical Report. United Nations De- 
partment of Economic and Social Affairs, Statistics Division.

[19] URT (2004) 2002 Population and Housing Census. Vol. 4, Regional and District Census Data in Brief. President's Office Planning and Privatization, Dar es Salaam.

[20] Mbilinyi, M. (1997) The End of Smallholder Farming? Gender and Structural Adjustment. TGNP Gender and Development Seminar Series, Dar es Salaam.

[21] URT (2011) Basic Facts and Figures on Human Settlements in Tanzania Mainland. National Bureau of Statistics, Dar es Salaam. http://www.nbs.go.tz/ 
Scientific Research Publishing (SCIRP) is one of the largest Open Access journal publishers. It is currently publishing more than 200 open access, online, peer-reviewed journals covering a wide range of academic disciplines. SCIRP serves the worldwide academic communities and contributes to the progress and application of science with its publication.

Other selected journals from SCIRP are listed as below. Submit your manuscript to us via either submit@scirp.org or Online Submission Portal.
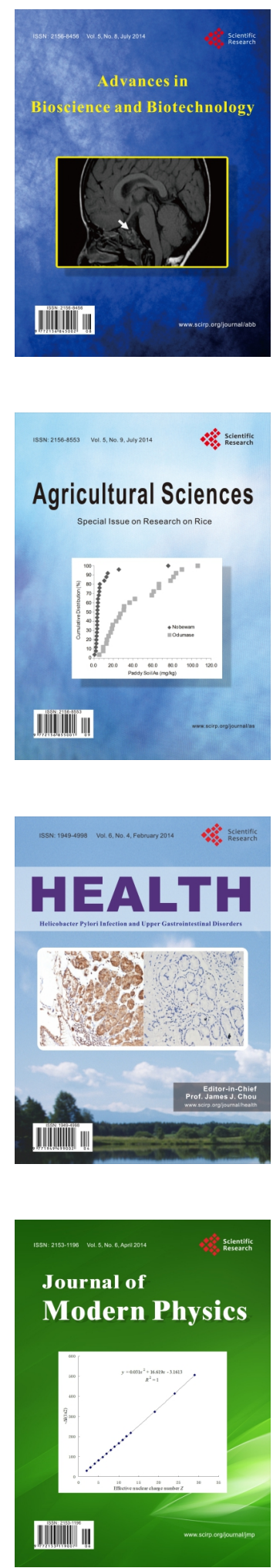
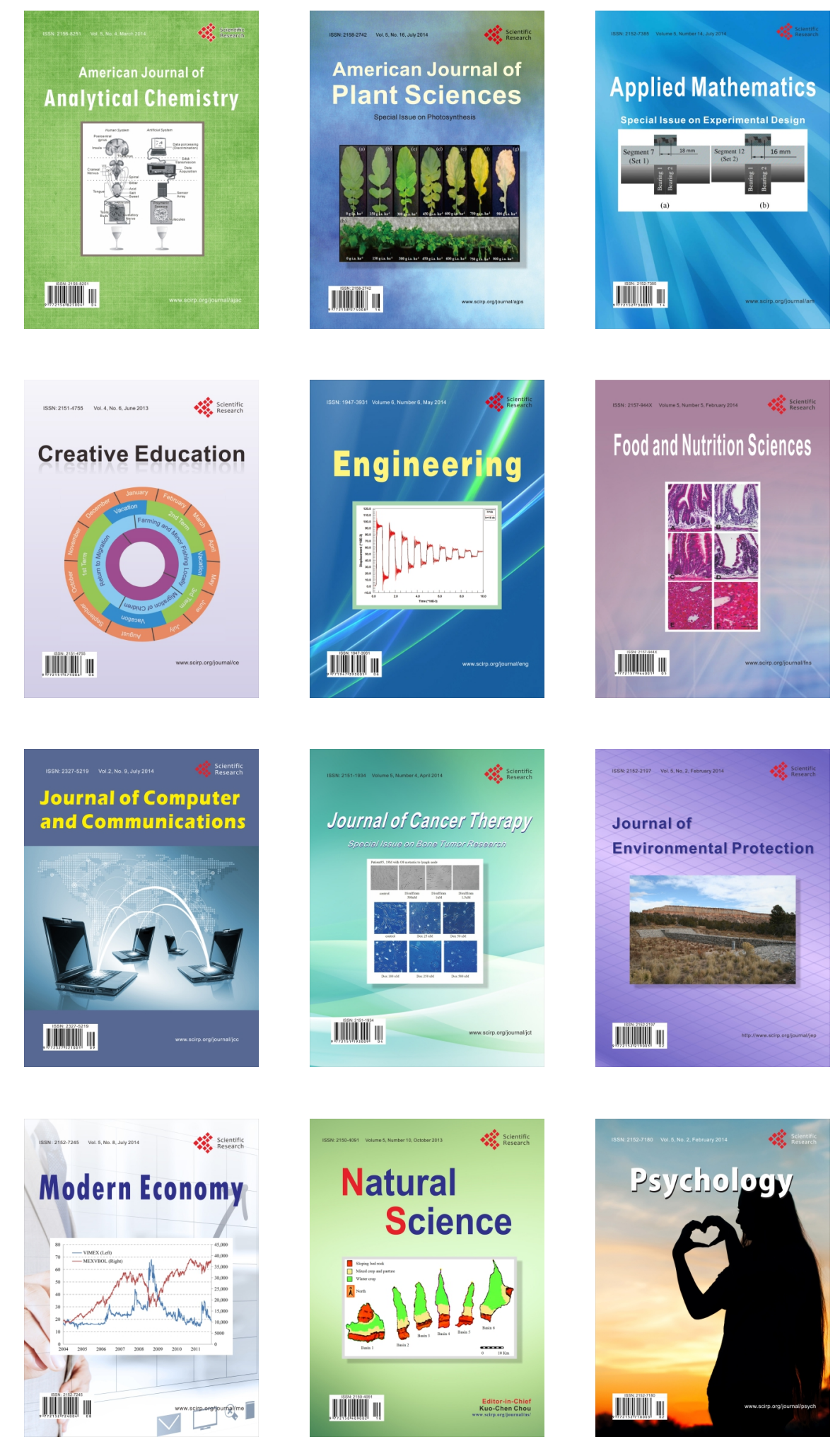